\title{
Professional Training Program Management through Holonic Networks
}

\author{
Jonás Montilva ${ }^{1}$, Milagro Rivero ${ }^{1}$, Judith Barrios ${ }^{1}$, Ana Martinez ${ }^{1}$, Isabel Besembel ${ }^{1}$ and \\ Beatriz Sandia ${ }^{2}$ \\ 1 Universidad de Los Andes, Facultad de Ingeniería, Escuela de Ingeniería de Sistemas, \\ Departamento de Computación, Grupo de Ingeniería de Datos y Conocimiento - GIDyC, \\ 5101 Mérida, Venezuela \\ ${ }^{2}$ Coordinación de Estudios Interactivos a Distancia (CEIDIS), Vicerrectorado Académico, \\ Universidad de Los Andes, Mérida, Venezuela \\ \{jonas, milagro, ijudith, ibc, bsandia\}@ula.ve
}

\begin{abstract}
Holonic networks constitute a type of organizational structures widely used at manufacturing enterprises. In an educational context, however, this type of structures remains practically unknown. The purpose of this paper is to demonstrate the applicability of these organizational structures to the design of professional training programs. Thus, we have herein proposed a conceptual model for holonic organizations that captures the structure and characteristics of this type of organizations. The use of this model is illustrated through the design of an academic organization devoted to professional training programs on Software Engineering. This paper describes the use of the combination of Holonic Networks and Business Models techniques for modeling complex organizational systems.
\end{abstract}

Keywords: Holonic networks, professional training programs, self-reliant organizations.

\section{Introduction}

The term "holon" refers to the basic unit of organization in biological and social systems. The term holon is a combination of the Greek word holos (whole) and the suffix on, meaning particle or part. A holon is an identifiable unit of a system, which at the same time is a system made up of subordinated parts [1].

The concept of holon has been widely used in both, intelligent manufacturing [2] and multi-agent systems [3]. The two basic properties of a holon are autonomy and cooperation. Each holon is autonomous in its decision-making and cooperates with other holons to meet the objectives of the system to which they belong.

In an entrepreneurial context, particularly in small and medium enterprises (SMEs), the concept of holon has enabled the creation of a type of flexible and dynamic organizational structure, which McHugh, Merli and Wheeler [4] called "virtual organization." A virtual organization is an entrepreneurial network with nodes made up of smaller organizations (holons) closely interrelated towards one or more common objectives.

We have discussed herein the applicability of holonic networks in the educational sector, particularly at university extension programs offering professional training.

In recent years, the supply and demand of E-learning professional training programs have grown significantly. A large number of Latin American colleges offer such programs on a regular basis. The design, operation and administration of a Professional Training Program (PTP) constitute a complex process that must be properly managed to guarantee the program effectiveness, efficacy, and efficiency.

Administration and operating processes require the structuring and execution of heterogeneous activities, such as academic administration, financial and accounting management, teaching, content design and LMS (Learning Management Systems) software administration, among others. Just like in the design process, PTP operation and administration processes are performed by individuals with dissimilar qualifications, who must cooperate and interact appropriately to guarantee the program success.

The purpose of this article is to demonstrate that holonic networks contribute to manage the complexity of PTP design, operation and administration. Therefore, a particular case study was selected: The Professional Training Program on Software Engineering at Universidad de Los Andes (Venezuela) [5][6].

The rest of this article is structured as follows: Section 2 describes, by means of a conceptual model, the concept of holonic organizations, as used in production enterprises. Section 3 summarizes the case study analyzed herein to illustrate the applicability of holonic networks in educational contexts. Section 4 introduces a PTP business model 
that together with the holonic network structure described in Section 5, illustrates how to manage a PTP. Finally, the concluding remarks are given in Section 6.

\section{Holonic Organizations}

In recent years, new processes for structuring organizations, using Information and Communication Technologies (ICTs), have arisen in order to improve internal business processes and speed up the interaction among related businesses. Virtual clusters and holonic organizations are two examples of these organizational structures. Clusters bring micro-businesses and/or SMEs (small and medium sized enterprises) together on an Internet website to manufacturing goods and/or providing services that would otherwise be impossible to achieve separately [4]. Holonic organizations bring one or more enterprises together with a common objective, forming a compound organizational structure. A virtual holonic organization is, therefore, made of a group of enterprises (companies or institutions) acting comprehensively to develop any business opportunity demanded by a client. Each participating company, known as holon, is responsible for executing one or more processes of the chain value required by the virtual organization [7].

Each holon has the ability to design and execute its own plans and define the strategies and activities required to perform the corresponding processes. Holons cooperate with each other to undertake all processes necessary for manufacturing the goods and/or providing the services requested from them.

Holonic organizations have a dynamic architecture that can be easily restructured to adapt to the client demands or to the changes imposed by their environment. In fig. 1, we propose a conceptual model that describes the general architecture of holonic organizations, as used in the production and service sectors of the economy. As indicated by the model, some of the most relevant properties of a holonic organization are the following:

- A holon is both a part and a whole, i.e., a holon is a network of holons that may be seen as resources used by the network to produce a required product (or provide a given service) in a cooperative and coordinated way.

- A holonic network configuration is determined by:

$\bigcirc \quad$ an organized set of production or service methods, known as business processes, and

- a set of resources.

- Each holonic unit develops one or more products or services, as required by the holonic network.

- To attend a given order, each holonic unit participating in the network applies one or more production/service methods (business processes) according to a predefined plan.

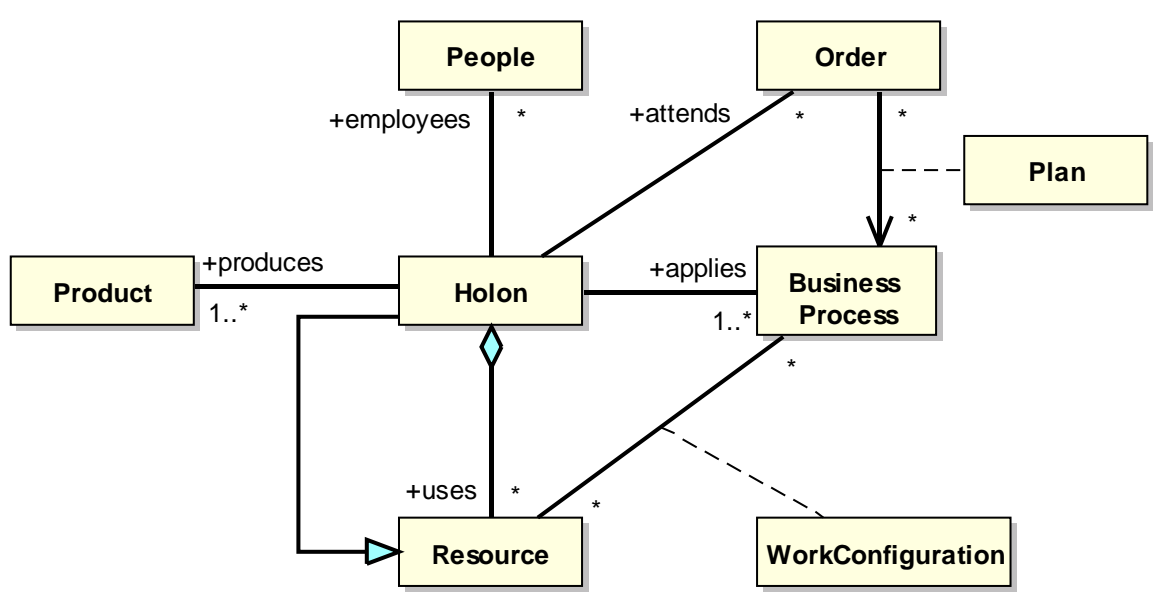

Figure 1. Conceptual model of holonic organizations

Holonic organizations are known for their structure called holarchy, in which each holon is an enterprise or business unit that is equal or similar to the other holons composing the holarchical network (self-similarity principle). Holons are also autonomous (self-regulated) and capable of learning. 


\section{Professional Training Programs (PTP)}

In order to describe the applicability of holonic networks in an educational context, specifically in the domain of university extension schools, a real-life case study was used: The Professional Training Program in Software Engineering, which due to time and space reasons, is referred to herein as the DINsoft Program, a university extension program created for professionals of the Computing and Systems Engineering fields and further related areas, interested in improving and updating their Software Engineering knowledge and competences.

A Professional Training Program (PTP), such as DINSoft, consists of a structured set of on-line courses associated with their application domain. The conceptual model described in Fig. 2 shows the basic components of a PTP.

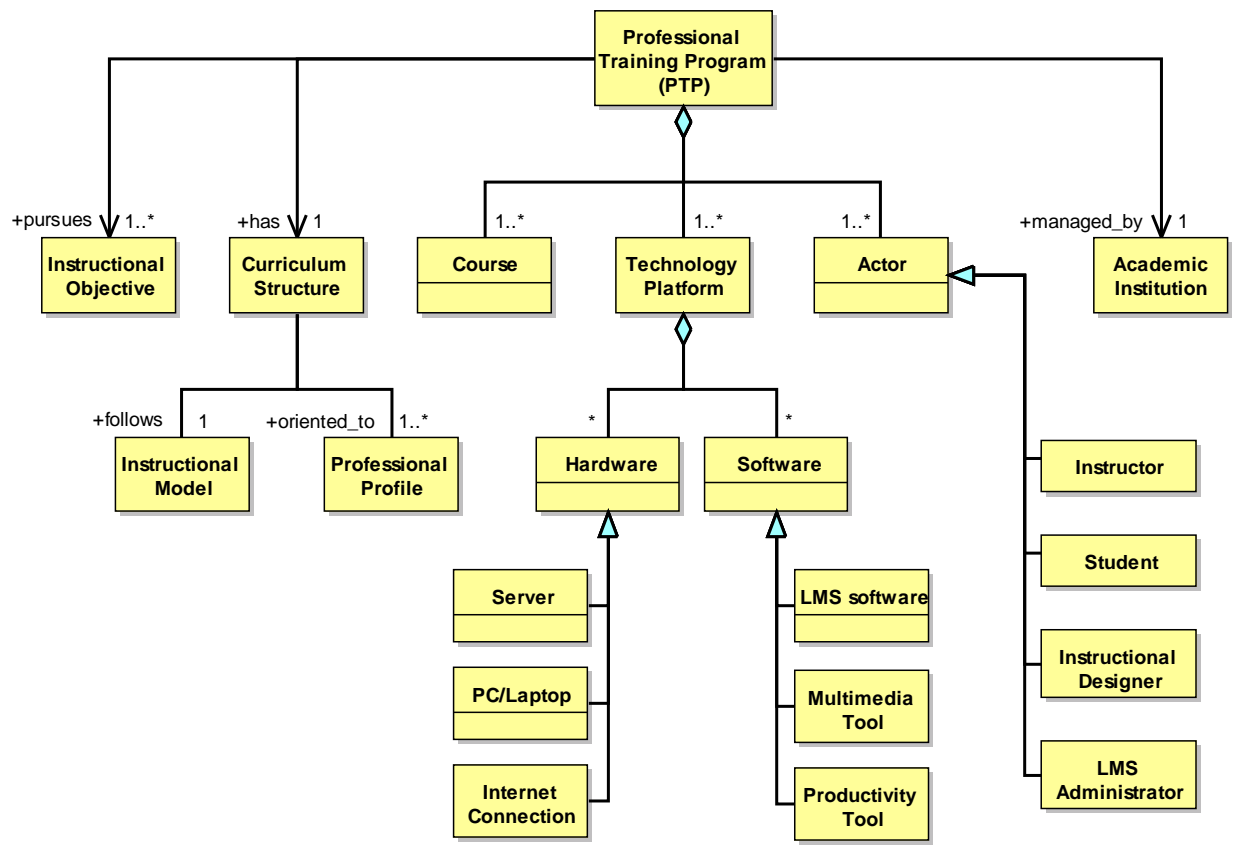

Figure 2. Conceptual Model of a Professional Training Program

A program of such nature has a curricular structure made up of a group of interrelated courses, which are implemented using an Internet-based technology platform. Several actors, such as the students enrolled in the program and the personnel in charge of course administration, maintenance and updating, partake in a PTP.

Fig. 3 shows the curricular structure designed for the DINSoft program, which is based on a set of four training profiles, defined through the analysis of Venezuelan software-developing companies [9]. These training profiles are: software project leader, software developer, support engineer, and software maintenance engineer.

This structure consists of five groups of non-excluding courses. The first group known as "Introductory Courses" is mandatory for all students or program participants. After having completed these courses, the participant chooses one of the four different lines relating to the professional profiles listed above.

\section{$4 \quad$ PTP Management Model}

PTP administration is a complex process, mainly due to the number of activities required for developing, operating, using and maintaining the program and, secondly, to the different competences that the personnel must possess for carrying out such activities.

To deal with the complexity of a PTP and manage it properly, it is necessary to clearly define all objectives, processes, actors and their organization, as well as the rules, technologies and resources required for their execution. In the case study analyzed herein, we developed a business model that describes each of the organization elements. This model is partially described in Figures 4 and 5 below.

The value chain presented in Fig. 4 identifies the business processes required to develop, operate, use, and maintain the program. Such processes are aimed at implementing the production and/or service methods mentioned in the conceptual model of the holonic network (See Section 2). 


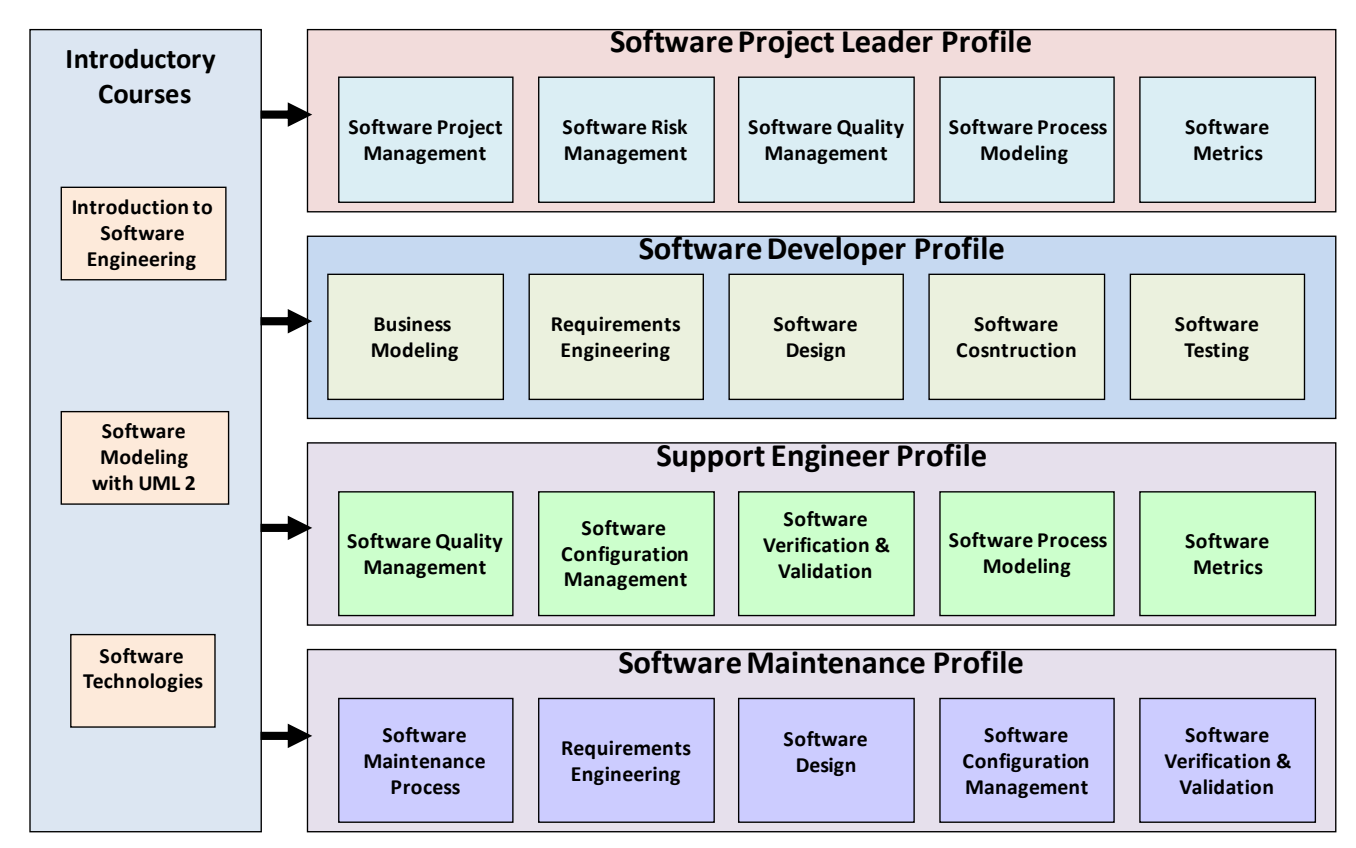

Figure 3. Curricular structure of the DINSoft program
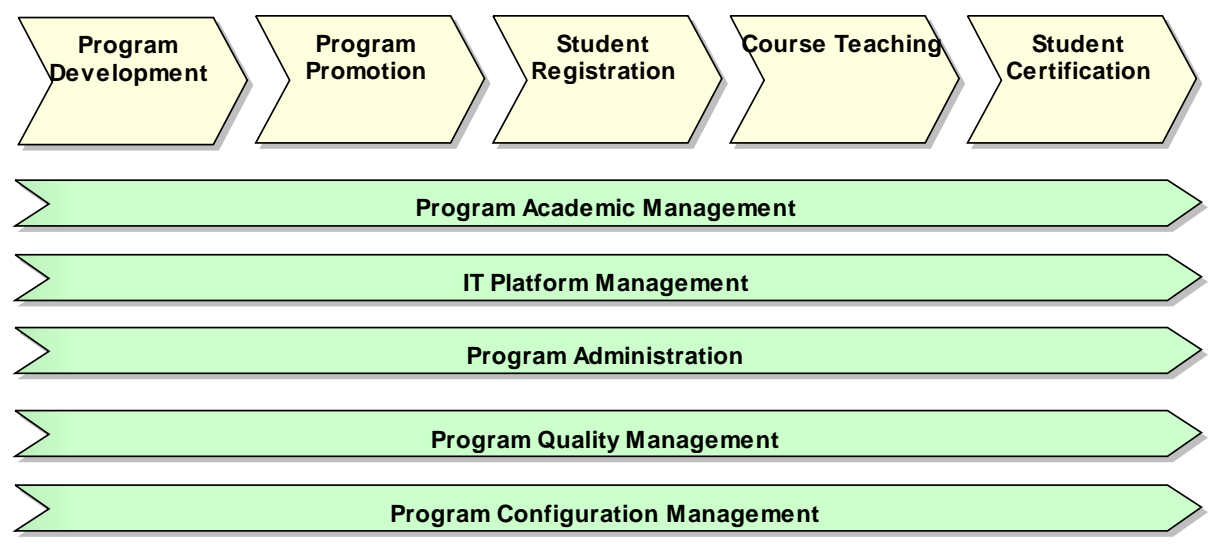

Figure 4. Value chain of the DINSoft Program showing the fundamental and support processes required to manage the program. Fundamental processes are shown at the top of the chain.

During the execution of each process, there is a set of related elements known as business objects that participates in its activities. Figure 5 identifies and relates the main business objects involved in the Program Academic Management process of the DINSoft program. As shown in this figure, PTPs are part of academic plans that describe the long term objectives, main activities, required resources and expected results of a virtual organization. There is a schedule associated to each PPT that indicates the initial and ending dates of each on-line course.

Each course is supported by a web instructional site that is designed, implemented and managed using a learning management system - LMS - (e.g. Moodle, ATutor and Claronline). The structure, content and learning activities of a course are normally designed by one or more authors who are assisted by an instructional designer. An LMS administrator gives technical support to the users of the web instructional site.

Depending on the instructional mode to be used in a given PTP, the instructor-student interaction may be completely at distance or hybrid (a combination of traditional and distance interaction). 


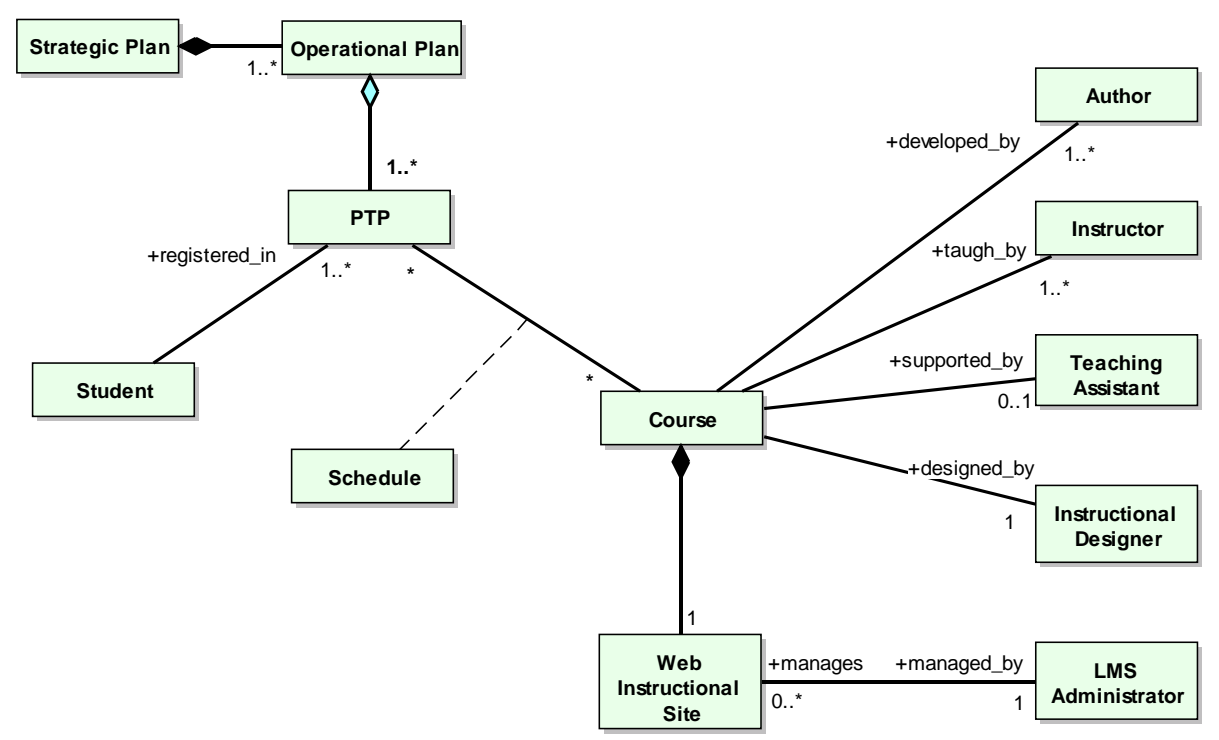

Figure 5. Business objects involved in the DINSoft Program Academic Management

\section{Holonic Organization of a PTP Program}

Each of the processes shown in the value chain (see Fig. 4) encompasses a group of activities performed by one or more actors. Depending on the process, actors may play different roles. In the case of DINSoft, some of the roles associated with the Program Development process are: program coordinator, content author, LMS administrator, and instructional designer.

Figure 6 shows how actors in a PTP play different kinds of roles. Such roles require specific competences (knowledge, skills, and abilities) in very dissimilar areas, such as: Instructional Design, System Administration, Elearning Education, Graphic Design, and Academic Management. In addition, there is also the particular PTP application domain knowledge, such as Software Engineering in the case of the DINSoft Program.

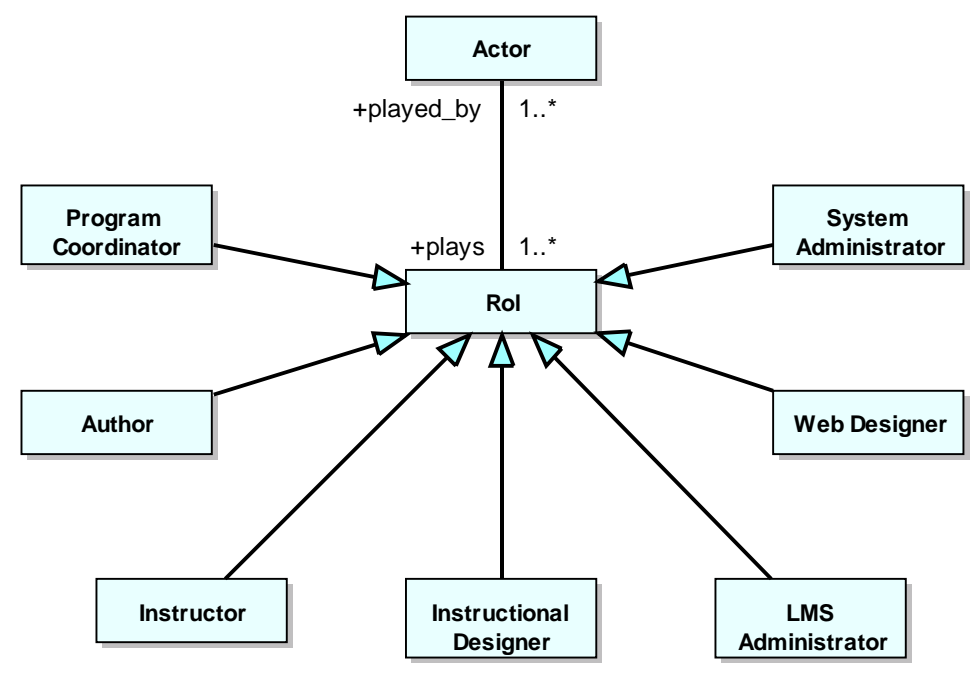

Figure 6. Main roles of the personnel in charge of the DINSoft Program

Assembling a PTP work team at our universities is a complex task, mainly due to two basic reasons: (1) Contracting new technical personnel and experienced professional is a complex administrative process that is restricted by the institution's budget deficiencies; (2) Professors are required to assume technical tasks such as system administration, graphical design and website administration, in addition to their teaching activities. 
Therefore, incorporating to a PTP team one or more specialized organizations, that are external to the university, becomes necessary. Holonic networks may contribute to this purpose by creating a more appropriate organizational structure.

In the case of DINSoft, we have proposed the holonic structure presented in Figure 7. This structure is an instantiation of the one presented in the conceptual model of holonic organizations shown in Fig. 1. Because of the instantiation, we only show a partial view of the whole set of objects that compose the DINSoft program. The holonic network consists of four resources (holons): a university postgraduate unit (ULA-CPP), a research group (GIDyC), an excellence center (CeiSoft) and a consulting company (BioSoft).

Each holon must contribute with its knowledge, expertise and competences to execute the processes of the DINSoft Program for which it is best prepared. For instance, the research group is in charge of developing the instructional contents of each course; meanwhile, the consultant company provides the instructional sites development and support.

These four holonic units negotiate with each other by means of the virtual network (theDinSofProgram). According to the abilities and level of preparation of each holonic unit, and the business processes to be performed, a work configuration is agreed, i.e. the group of processes for which each holonic unit will be responsible.

Such configuration consist of the association between the business process or sub-processes to be performed and the resources (holons) assuming the responsibility for their execution.

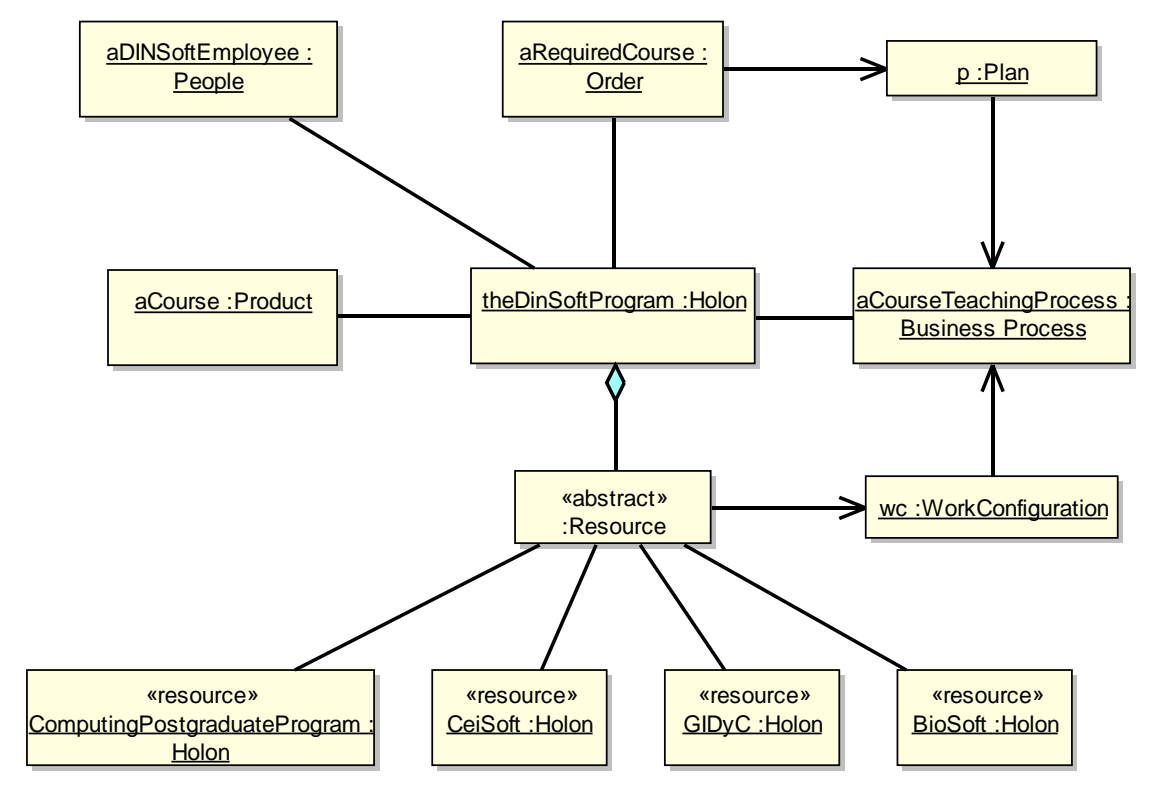

Figure 7. Holonic structure of the DINSoft Program

Once the order negotiation is agreed (e.g. a course request), such order is stored in the work plan of the virtual enterprise. Then, each unit stores in its internal planning all commitments acquired, recording their start-up and completion dates and product quantity (or service quality) included in its regular functions.

Each holonic unit uses its own resources to comply with the agreements established and delivers the products or services on the agreed-upon dates.

Table 1 illustrates the distribution of some of the functions associated with the execution of processes and activities among the four holons forming the DINSoft Program organizational structure:

- The ULA Computing Postgraduate Program (ULA-CPP)

- A Software Engineering excellence center (CeiSoft)

- A Software Engineering research group (GIDyC)

- A software consulting company (BioSoft)

Such distribution was based on the potential ability of each holon to perform the process and or activity assigned. Each holonic unit is responsible for executing these processes autonomously within the terms agreed. 
Table 1. Business processes assignment to the DINSoft Program organization holons. A letter E, shown in a $(i, j)$ cell, means that the holon indicated by the $j$ column is responsible for the execution of the processs indicated by the $i$ row

\begin{tabular}{|c|c|c|c|c|c|}
\hline Process & Activities & ULA-CPP & GIDyC & CeiSoft & BIOSoft \\
\hline \multirow{5}{*}{$\begin{array}{l}\text { Program } \\
\text { Development }\end{array}$} & Course Design & $\mathrm{E}$ & & & \\
\hline & $\begin{array}{l}\text { Instructional Site } \\
\text { Development }\end{array}$ & & & & $\mathrm{E}$ \\
\hline & Content Creation & & $\mathrm{E}$ & & \\
\hline & $\begin{array}{l}\text { Instructional Site } \\
\text { Assembly }\end{array}$ & & & & $\mathrm{E}$ \\
\hline & Course Evaluation & $\mathrm{E}$ & & & \\
\hline \multirow[t]{3}{*}{$\begin{array}{l}\text { Program } \\
\text { Promotion }\end{array}$} & $\begin{array}{l}\text { Promotional } \\
\text { Camnaion Desion }\end{array}$ & & & $\mathrm{E}$ & \\
\hline & $\begin{array}{l}\text { Promotional } \\
\text { Campaign } \\
\text { Execution }\end{array}$ & & & $\mathrm{E}$ & \\
\hline & $\begin{array}{l}\text { Promotional } \\
\text { Campaign } \\
\text { Evaluation }\end{array}$ & $\mathrm{E}$ & & & \\
\hline
\end{tabular}

\section{Conclusions}

The organization of a Professional Training Program (PTP) is a complex task, as different factors in the university environment have direct impact thereon. Specifically, the variety of PTP competences and activities makes a holonic organization a suitable structure for managing and operating a PTP.

In this paper, we have illustrated the application of holonic organization models for academic program administration. The main benefits of using the model proposed herein relate to the structure's ability to integrate the efforts of the different organizations that cooperate and interoperate for meeting the objectives of the holonic network. A potential risk of using the proposed model, particularly in a Latin-American business environment, may relate to the level of organizational maturity required, as organizations taking part in such networks must reach a high level of maturity and compromise that is needed to assume and timely fulfill the responsibilities of the participating holons.

Future projects on this subject would deal with the assessment and improvement of the model proposed through its application to DINSoft and other similar programs, such as the one developed by the company BIOSoft through the e-Praxis program [10].

Acknowledgements. The authors wish to thank Fondo Nacional de Ciencias, Innovación y Tecnología de Venezuela (FONACIT), under Project $\mathrm{N}^{\circ}$ 2005000165, and Consejo de Desarrollo Científico, Humanístico y Tecnológico (CDCHT) of Universidad de Los Andes, under the ADG Program, for co-financing this project, which served as a framework for the preparation of this paper.

\section{References}

[1] HMS: Holonic Concepts. Holonic Manufacturing Systems - HMS Consortium. University of Hannover, Alemania. [online]. http://hms.ifw.uni-hannover.de/ (2007)

[2] Bongaerts, L.: Integration of Scheduling and Control in Holonic Manufacturing Systems, Ph.D. Thesis PMA/K.U.Leuven, Chapter 3. (1998)

[3] Ulieru, M., Stefanoiu, D., Norrie, D.: Holonic self-organization of multi-agent systems by fuzzy modeling with application to intelligent manufacturin. In: IEEE International Conference on Systems, Man, and Cybernetics, Volume 3, pp. $1661-1666(2000)$

[4] McHugh, P., Merli, G., Wheeler, W.A.: Beyond Business Process Reengineering: Towards the Holonic Enterprise. John Wiley \& Sons, England (1995)

[5] Montilva, J., Sandia, B., Martínez, A., Rivero, D., Barrios, J., Besembel, I: Diseño de programas de actualización profesional interactiva a distancia. Actas del 1er. Congreso Internacional de Calidad e Innovación en Educación Superior (CIES2007) y VI Reunión nacional de Currículo. Caracas, Venezuela (2007) 
[6] Montilva J., Barrios, J., Rivero, M., Besembel, I., Martínez, A., Sandia., B.: Dinsoft: un programa de actualización profesional en ingeniería de software. In: Actas de las VI Jornadas Científico-Técnicas de la Facultad de Ingeniería, Universidad de Los Andes, Mérida, Venezuela, , Artículo No. JI-IS-030, pp-1027-1035. (2007)

[7] Chacón, E., Besembel, I., Rivero, M., Cardillo, J: The Holonic Production Unit: an Approach for an Architecture of Embedded Production Process. In: Advances in Robotics, Automation and Control, ITech_ISA. Chapter 16, pp 301-314. (2008)

[8] Sandia, B., Montilva, J.: Los estudios interactivos a distancia en la Universidad de Los Andes. Revista Acción Pedagógica. Vol. 11, No. 1, Enero-Junio. (2002)

[9] Rivero, D., Montilva, J., Granados, G., Barrios, J., Besembel, I., Sandia, B.: La Industria de Software en Venezuela: Una caracterización de su recurso humano". In: Losavio, F et al (EDS). Actas del X Workshop Iberoamericano de Ingeniería de Requisitos y Ambientes de Software (IDEAS'07) y del Primer Encuentro Venezolano sobre Tecnologías de Información e Ingeniería de Software (EVETIS'07). Porlamar, 7-11 pp. 435-443. (2007)

[10] BIOSOFT. Programa de Actualización Profesional en Ingeniería del Software e-Praxis. http://e-praxis.biosoftca.com 